\title{
Fallow Controls Nematodes In Tomato Production ${ }^{1}$
}

A successful tomato-growing industry has been developed in southern Puerto Rico in an area adjacent to Santa Isabel. Soils in that area are generally infested with a complex of root lesion, dagger, root knot, spiral and other ecto- and endoparasitic nematodes. Extensive applications of soil fumigants had made no appreciable difference in production which generally was very satisfactory.

Tomatoes follow sugarcane after the crop had been growing for 3 or 4 years. Cane stubble is broken with heavy-duty Rome diskplows which turn over the soil to a depth of 12 inches, breaking the stubble into small fragments. After 2 weeks exposure to the hot temperatures of the region, a second plowing is made and exposed for 2 or 3 weeks, when a subsoiler is run to a depth of 14 to 16 inches. After a third period of drying, fields are again worked with the Rome plow, followed in 2 or 3 weeks by seed preparation with lighter disks and harrows.

Extensive soil-sampling revealed that, after tillage operations, only 5 to 10 percent of the original populations of nematodes remained, and that during the tomato-growing period from October through May, there was insufficient recovery to cause appreciable damage.

Tomatoes are grown in that area by direct seeding in the field beginining in early October and extending through December. Irrigation water is applied as needed, since there is insufficient rainfall during those months. It was not until March 12 that the first small galls of root knot were found where larval nematodes had apparently come up from the undisturbed soil below. In late April and May galls were well developed on many plants, but by that time harvest was well underway and there was no appreciable reduction in yjelds.

1 This project was made possible by a grant from Productos Libby's Inc. of Puerto Rico to the Estación Experimental Agrícola, Río Piedras, P.R. The company cooperated in applying soil fumigants, planting, growing, and harvesting the large-scale field plots. Thanks are especially due to Mr. Otto Bundy, Manager; Mr. Ralph Moltzau, in research; and Mr. George Lawrence, in production. Mr. Martin Capella supervised the laborious task of harvesting. Shell Chemical Corp. determined moisture equivalents of the soils. 
Soil-fumigation experiments were conducted under the sponsorship of Productos Libby's Inc. of Puerto Rico. Applications of Shell D.D. in amounts ranging from 30 to $\mathbf{1 0 0}$ gallons per acre were made on large field plots, but in no instance was there tonnage increase sufficient to justify the expense. In many instances there was no increase whatever in yield. Failure of response to fumigants occurred in part because the soils are heavy clays with moisture equivalents ranging from 28 to 44 percent.

Fallow under Santa Isabel conditions obviously gives excellent control for nematodes in tomatoes and doubtless would be just as efficient for any other annual crop. This system has long been practiced in the winter vegetable-producing areas of the Imperial and Coachella Valleys of California, in Southern Arizona and the Rio Grande Valley of Texas.

Gerald Thorne and Jessé Román Department of Entomology 